九州大学学術情報リポジトリ

Kyushu University Institutional Repository

\title{
Effect of Heat Treatment on the Acoustic Properties of a Wooden Xylophone Keyboard
}

\section{Kang, Ho-Yang}

Department of Bio-based Materials, Chungnam National University

Kang, Chun-Won

Department of Housing Environmental Design, and Research Institute of Human Ecology, College of Human Ecology, Chonbuk National University

Hong, Seung-Hyun

Department of Bio-based Materials, Chungnam National University

Matsumura, Junj i

Laboratory of Wood Science, Division of Sustainable Bioresources Science, Department of Agroenvironmental Sciences, Faculty of Agriculture, Kyushu University

https://doi.org/10.5109/1564098

出版情報：九州大学大学院農学研究院紀要. 61 (1)，pp.157-163，2016-02-29. Faculty of Agriculture, Kyushu University

バージョン :

権利関係 : 


\title{
Effect of Heat Treatment on the Acoustic Properties of a Wooden Xylophone Keyboard
}

\author{
Ho-Yang KANG ${ }^{1}$, Chun-Won KANG ${ }^{2 *}$, Seung-Hyun HONG ${ }^{1}$ \\ and Junji MATSUMURA
}

\author{
Laboratory of Wood Science, Division of Sustainable Bioresources Science, \\ Department of Agro-environmental Sciences, Faculty of Agriculture, \\ Kyushu University, Fukuoka 812-8581, Japan \\ (Received November 11, 2015 and accepted November 19, 2015)
}

\begin{abstract}
To estimate changes in the acoustic properties of a wooden xylophone keyboard caused by heat treatment, the resonant frequencies and logarithmic decrement of control and heat-treated specimens of Yezo spruce (Picea jezoensis), Northern red oak (Quercus rubra) and Japanese red pine (Pinus densiflora S. et Z.) were evaluated by the free vibration method. A flexural vibration test was carried out by the xylophone stick free fall impact test. The changes in resonant frequency of the first mode and those of other modes by heat treatment were evaluated. And the changes in logarithmic decrement by heat treatment were evaluated.

As a result of heat treatment, the resonant frequencies of the 1st mode of all specimens were decreased, and within a species the wood specimens of higher resonant frequencies were more influenced. In the case of the specimen with a higher resonant amplitude at the 2 nd mode resonance frequency, the resonant amplitude of the 1st mode resonance frequency was increased more by heat treatment, so that the sound became more stable.
\end{abstract}

Key words: heat treatment, resonant frequency, acoustic property

\section{INTRODUCTION}

Wooden musical instruments have been developed over the history of mankind. Wood is often used as a sounding material for its relatively easy machinability, unique resonance, proper damping ratio, proper harmonic series and sound radiation features. Although many kinds of wooden materials have been replaced by iron, plastic and other synthetic materials, wooden musical instruments cannot be entirely replaced by other materials because of their unique sound color and acoustic properties.

It is generally recognized that wood is lightweight and its elastic modulus is relatively high compared to other materials. Many researchers (Kang et al., 2008; Kang and Jung, 1988; Norimoto, 1982, 1987; Okano, 1991; You and Jung, 1997; Yano, 1992) reported that the ratio of the modulus of elasticity to wood density greatly influences the acoustic properties of wood. Western wooden musical instruments like the violin, cello, xylophone and marimba use a wooden sounding board. A xylophone is classified as a percussive musical instrument though it has a keyboard. In general, percussive musical instruments cannot produce pitch, but the xylophone can. This pitch is generated by the percussion of different sizes of wood sounding keys. Therefore, the xylophone's pitch varies by the size, weight and vibrational properties of the

\footnotetext{
1 Department of Bio-based Materials, Chungnam National University, Daejeon 305-764, Korea

2 Department of Housing Environmental Design, and Research Institute of Human Ecology, College of Human Ecology, Chonbuk National University, Jeonju 561-756, Korea

* Corresponding author: Chun-Won KANG (E-mail: kcwon@ jbnu.ac.kr)
}

wooden keys. The marimba has a relatively wide range of six octaves provided by a rosewood board, and it can create rich and beautiful sounds via a sound box.

Sounding boards or musical instruments were sometimes traditionally treated with heat to improve acoustic properties. However, the research regarding the influence of heat treatment conditions such as heating temperature, heating time and heating method on wooden musical sounding boards was rarely observed. Tjeerdsma et al. (1998) reported that the heating temperature is the most influential parameter of heat treatment for wood. Wikberg and Maunu (2004) reported that the wood structure was condensed by heat treatment because cellulose crystallinity increases due to the degradation of amorphous cellulose, and the lignin structure change and the reduction in methoxyl group content. Kim et al. (2011) adopted low temperature heat treatment to modify the acoustic properties without seriously degrading wood components and to improve the acoustic properties of sounding materials. With this treatment, degraded hemicelluloses change the hygroscopic behavior of wood, which in turn decreases the equilibrium of the moisture content. Yano et al. $(1986,1990)$ reported that the changes in the hygroscopic behavior of wood contribute to more stable acoustic properties.

Norimoto (1982) indicated that sounding boards described as good by a piano expert have a low ratio of internal friction to dynamic $\operatorname{MOE}\left(Q^{-1} / E^{\prime}\right)$, and this value correlates well with the ratio of dynamic MOE to density, $\mathrm{E} / \rho$. Here the dynamic MOE value is calculated from the resonant frequency, sample size and density with Hearmon's equation (1966)

From these results, to estimate the influence of heat treatment on the wooden xylophone sounding board, we 
estimated the changes in acoustic properties caused by heat treatment with comparison between control and treated specimens. This study was limited to small specimens and to determining the changes in acoustic properties such as resonant frequencies and logarithmic decrement of heat-treated wood for a xylophone sounding board. Furthermore, we evaluated the influence of heat treatment temperature for wooden xylophone keyboards.

\section{MATERIALS AND METHODS}

\section{Preparing Specimens}

Three different species were selected for this study: Japanese red pine (Pinus densiflora), Northern red oak (Quercus rubra) and Yezo spruce (Picea jezoensis). Air-dried boards $30 \mathrm{~mm}$ in thickness were obtained and oven-dried at $103 \pm 2{ }^{\circ} \mathrm{C}$. They were cut and four-side planed into long pieces with width of $24 \mathrm{~mm}$ and thickness of $11 \mathrm{~mm}$. Eight defect free and straight-grained specimens of each species were cross-cut from the long pieces. Their lengths differed to produce various pitches, ranging from $148 \mathrm{~mm}$ to $211 \mathrm{~mm}$ in intervals of $9 \mathrm{~mm}$ (Table 1). The dimensions of the specimens were calculated from a commercially available wooden xylophone whose notes ranged from a 5th octave "Do" to a 6th octave "Do" (Figure 1)

\section{Measuring oven-dry densities}

The oven-dry densities of the specimens were calculated by using Eq. [1]. Their oven-dry volumes were obtained from their dimensions, and their oven-dry weights were measured after cross-cutting.

$\rho_{\text {od }}=W_{\text {od }} / V_{\text {od }} \longrightarrow[1]$

where $\rho_{\text {od }}$ is an oven-dry density $\left(\mathrm{g} / \mathrm{cm}^{3}\right), W_{\text {od }}$ is an

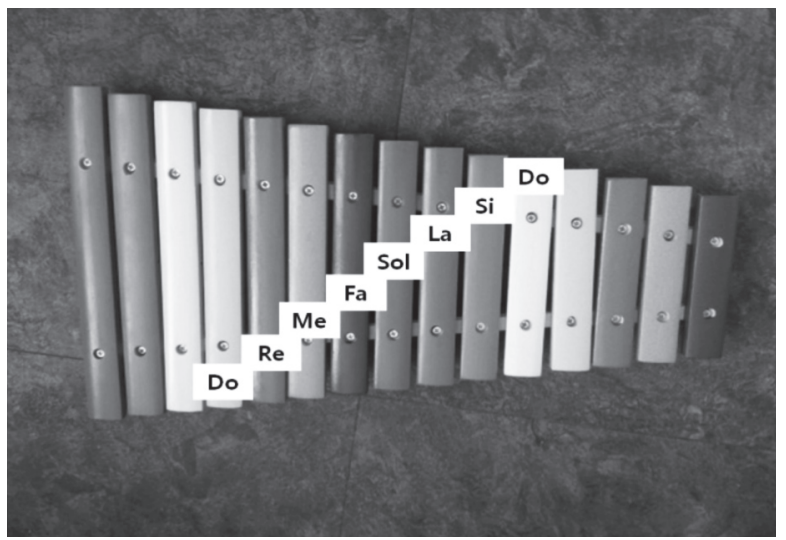

Fig. 1. A wooden xylophone. oven-dry weight and $V_{\text {od }}$ is an oven-dry volume.

\section{Heat treatment}

Heat treatment was carried out in a laboratory type heating unit with internal dimensions of $700 \times 800 \times$ $600 \mathrm{~mm}$, which was controlled to an accuracy of $\pm 1^{\circ} \mathrm{C}$ under atmospheric pressure. The maximum heating temperature of the unit was $220^{\circ} \mathrm{C}$, and the air velocity on the stacks was $4 \mathrm{~m} / \mathrm{s}$. Relative humidity was not controlled. Two different temperature schedules were adopted for heat treatment: for HT170, temperature was raised from ambient to $120^{\circ} \mathrm{C}$ over an hour, was raised to $170^{\circ} \mathrm{C}$ over five hours, and then the temperature of $170^{\circ} \mathrm{C}$ was continued for 2 hours; for HT190, temperature was raised from ambient to $120^{\circ} \mathrm{C}$ over an hour, was raised to $190^{\circ} \mathrm{C}$ over 3 hours, and then the temperature of $190^{\circ} \mathrm{C}$ was continued for 2 hours (Figure 2). All specimens were heat treated four times, three times with HT170 and the last time with HT190.

\section{Acoustic signal analysis}

The acoustic properties of wood are influenced by its dynamic modulus of elasticity and damping ratio. The dynamic modulus of elasticity is proportional to the resonant frequencies of wood. These resonant frequencies of wood specimens were estimated from the transverse vibration of the small wooden board with xylophone stick free fall tests. The apparatus setup for signal acquisition consists of a condenser microphone (Cirrus MK224, England) and a digital oscilloscope (Tektronix DPO4034 $250 \mathrm{MHz}$, Japan). The specimen was put on a base plate and supported by soft sponge to prevent reflecting waves from the floor as shown in Figure 3. The microphone was $15 \mathrm{~cm}$ from the sample specimen, and the xylophone stick was dropped from $10 \mathrm{~cm}$ above the wooden sample specimen. The microphone detected the signal from the

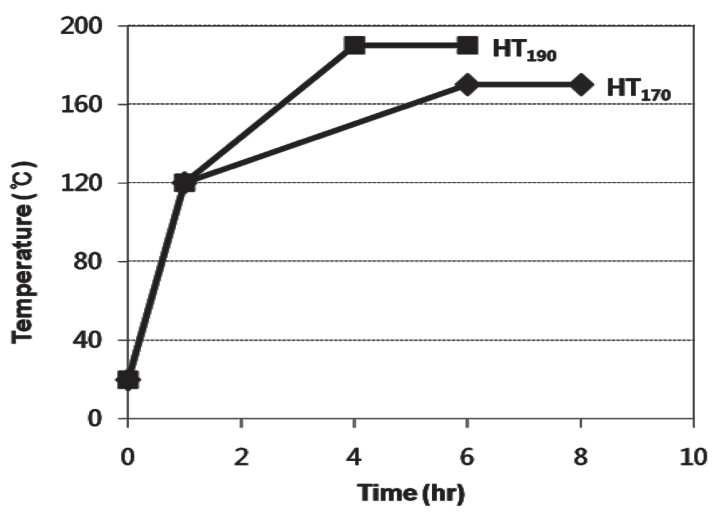

Fig. 2. Heat treatment schedules used for this study.

Table 1. The lengths of the specimens and their corresponding notes of a wooden xylophone

\begin{tabular}{lccccccccc}
\hline Specimen No. & 1 & 2 & 3 & 4 & 5 & 6 & 7 & 8 \\
\hline Length (mm)a & 211 & 202 & 193 & 184 & 175 & 166 & 157 & 148 \\
Note of the wooden xylophone & Do & Re & Me & Fa & Sol & La & Si & Do \\
\hline
\end{tabular}


wooden sample, the oscilloscope received this signal and a frequency response curve was achieved by FFT (Fast Fourier Transform) analysis. This test was repeated three times for each specimen, and the obtained data were averaged. From the spectral analysis, the resonant frequency of each small wooden board was estimated. We did not consider the influence of shear deflection or rotary inertia on the free flexural vibration of wooden boards caused by the difference in the ratio of sample thickness to length; we focused only on the influence of heat treatment on the sounding board. Also, to analyze the effect of heat treatment temperature on the resonant frequency of the wooden board, we compared changes in the resonant frequency due to different heat treatment schedules.

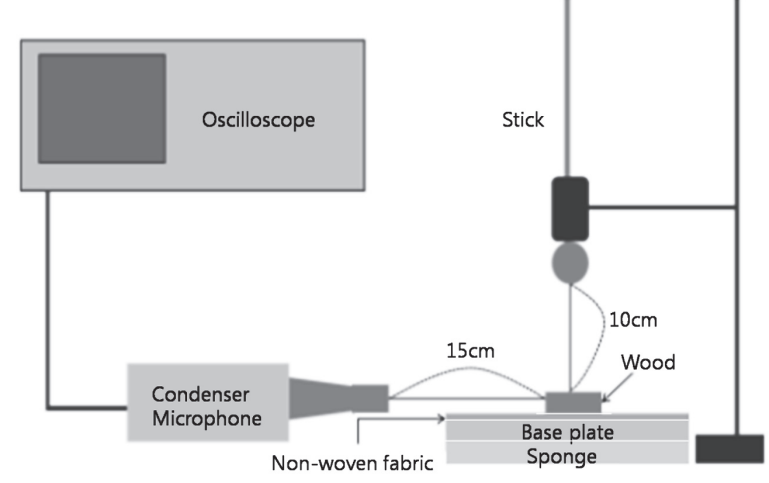

Fig. 3. Schematic diagram of the apparatus set-up for measuring the acoustic properties of the specimens.

In addition, we measured changes in logarithmic decrement of the wooden board by heat treatment. Experimental estimation of logarithmic decrement was based on the amplitude of two vibrations several cycles apart from the time domain amplitude decay curve, as shown in Figure 4. The logarithmic decrement was computed using Eq. [2].

$$
\delta=\frac{\ln \left(\frac{A_{1}}{A_{2}}\right)}{\Delta C}
$$

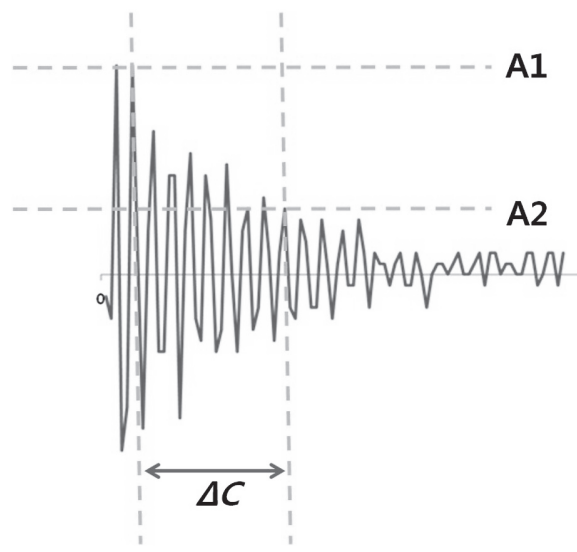

Fig. 4. A waveform of an acoustic signal. where $\delta$ is logarithmic decrement, $A$ is Amplitude, and $\Delta C$ is the wave number between $A_{1}$ and $A_{2}$.

\section{RESULTS AND DISCUSSION}

\section{Effect of an oven-dry density on 1st resonance fre- quency}

Figure 5 shows a typical waveform of an acoustic signal obtained by the digital oscilloscope, and its frequency response curve. From the power spectrum (the right graph in Figure 5), the resonance frequencies of the 1st, 2nd, 3rd and so on, modes were obtained.
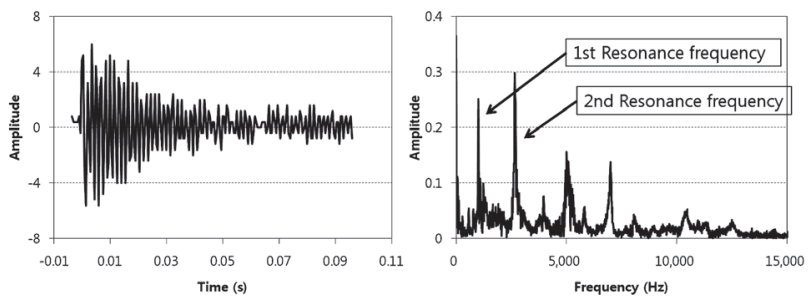

Fig. 5. A typical waveform and frequency response curve of an acoustic signal.

The 1st mode resonance frequencies of the control specimens are plotted in Figure 6. Within a species there are highly correlative proportional relationships between the 1st mode resonance frequencies and the specimen number, which correspond to the various lengths of the specimens. The oven-dry densities of the control specimens were $0.37,0.70$ and $0.61 \mathrm{~g} / \mathrm{cm}^{3}$ for spruce, red oak and pine, respectively. Thus, it was revealed that higher oven-dry densities correspond to lower 1st mode resonance frequencies at various lengths of the specimens.

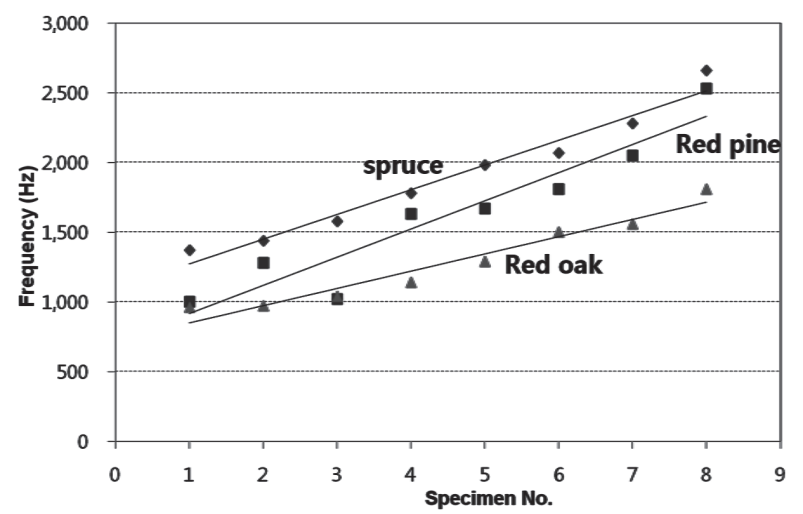

Fig. 6. Comparison of the $1^{\text {st }}$ mode resonance frequencies between three species at various pitches.

\section{Effect of heat treatment on the 1st mode resonance frequency}

Table 2 lists the differences of the 1 st mode resonance frequencies between heat-treated and control specimens. The 1st mode resonance frequencies decrease as the repetitions of heat treatment increase, and they show agreement with negative linear relationships (Figure 
7). Table 2 shows that the absolute values of the slopes of the linear regressions roughly increase with the increase of the 1st mode resonance frequencies of the controls. This means that the shorter specimens having higher 1st mode resonance frequencies are more influenced by the repetition of heat treatment.
Figure 8 shows that the differences between the 1st mode resonance frequencies of the $\mathrm{H} 4$ specimens (heat treated four times) and those of the controls increase as the pitches of the specimens increase for all species. This confirms that the specimens of higher pitches are more affected by heat treatment. Within a species, the spruce
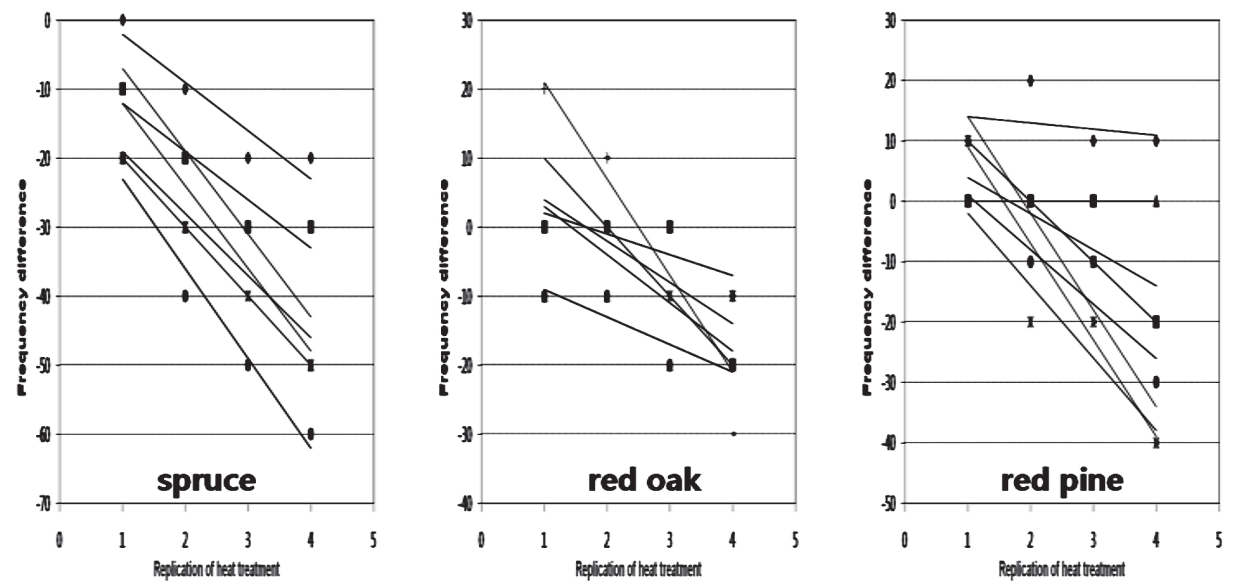

Fig. 7. Relationship between heat treatment repetition and $1^{\text {st }}$ mode resonant frequency of spruce, red oak and red pine.

Table 2. The differences of the 1 st mode resonance frequencies between the heat treated and the control specimens

\begin{tabular}{|c|c|c|c|c|c|c|c|c|}
\hline \multirow{2}{*}{ Species } & \multirow{2}{*}{$\begin{array}{l}\text { Specimen } \\
\text { no. }\end{array}$} & \multirow{2}{*}{$\begin{array}{l}\text { The } 1 \text { st mode } \\
\text { resonance frequency of }- \\
\text { the control }\end{array}$} & \multicolumn{4}{|c|}{ Repetition of heat tretment } & \multicolumn{2}{|c|}{ Linear regression } \\
\hline & & & $\mathrm{H} 1$ & $\mathrm{H} 2$ & H3 & $\mathrm{H} 4$ & Slope & $\mathrm{R}^{2}$ \\
\hline \multirow{8}{*}{ spruce } & 1 & 1,370 & 0 & -10 & -20 & -20 & -7.0 & 0.9 \\
\hline & 2 & 1,440 & -10 & -20 & -30 & -30 & -7.0 & 0.9 \\
\hline & 3 & 1,580 & -20 & -30 & -30 & -50 & -9.0 & 0.9 \\
\hline & 4 & 1,780 & -10 & -30 & -30 & -50 & -12.0 & 0.9 \\
\hline & 5 & 1,980 & -20 & -30 & -40 & -50 & -10.0 & 1.0 \\
\hline & 6 & 2,070 & -20 & -40 & -50 & -60 & -13.0 & 1.0 \\
\hline & 7 & 2,280 & -10 & -20 & -20 & -50 & -12.0 & 0.8 \\
\hline & 8 & 2,660 & -20 & -40 & -50 & -60 & -13.0 & 1.0 \\
\hline \multirow{8}{*}{ red oak } & 1 & 960 & 0 & 0 & 0 & -10 & -3.0 & 0.6 \\
\hline & 2 & 970 & 0 & 0 & 0 & -20 & -6.0 & 0.6 \\
\hline & 3 & 1,040 & -10 & -10 & -20 & -20 & -4.0 & 0.8 \\
\hline & 4 & 1,140 & 0 & 0 & 0 & -10 & -3.0 & 0.6 \\
\hline & 5 & 1,290 & 0 & 0 & -10 & -20 & -7.0 & 0.9 \\
\hline & 6 & 1,500 & -10 & -10 & -20 & -20 & -4.0 & 0.8 \\
\hline & 7 & 1,560 & 20 & 10 & -10 & -20 & -14.0 & 1.0 \\
\hline & 8 & 1,810 & 0 & 10 & 0 & -30 & -10.0 & 0.6 \\
\hline \multirow{8}{*}{ red pine } & 1 & 1,000 & 10 & 20 & 10 & 10 & -1.0 & 0.1 \\
\hline & 2 & 1,280 & 0 & 0 & 0 & -20 & -6.0 & 0.6 \\
\hline & 3 & 1,020 & 0 & 0 & 0 & 0 & 0.0 & 0.0 \\
\hline & 4 & 1,630 & 10 & 0 & -10 & -20 & -10.0 & 1.0 \\
\hline & 5 & 1,670 & 0 & -20 & -20 & -40 & -12.0 & 0.9 \\
\hline & 6 & 1,810 & 0 & -10 & -10 & -30 & -9.0 & 0.9 \\
\hline & 7 & 2,050 & 10 & 0 & -10 & -40 & -16.0 & 0.9 \\
\hline & 8 & 2,530 & 10 & -10 & -20 & -40 & -16.0 & 1.0 \\
\hline
\end{tabular}


specimens were most affected by heat treatment at all pitches, while the red oak specimens were least affected.

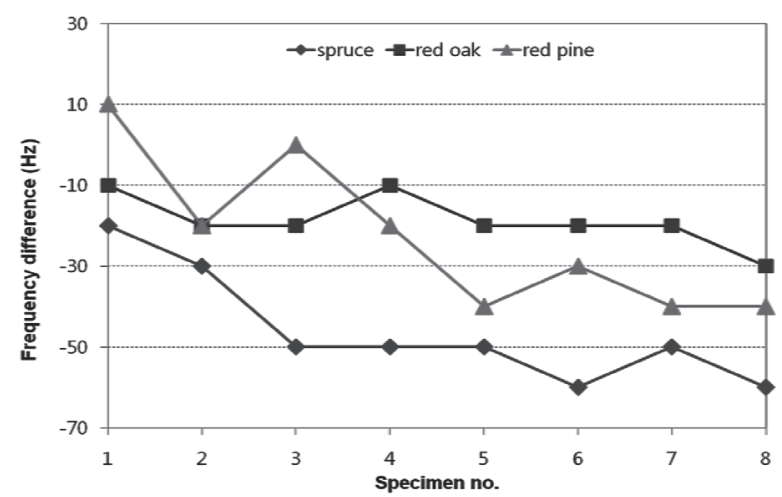

Fig. 8. The differences of the 1 st mode resonance frequencies between the $\mathrm{H} 4$ and the control specimens.

Effect of heat treatment on the amplitude of the resonance frequency

The amplitudes of the 1st mode resonance frequencies range from 0.55 to 2.94 for spruce, from 0.23 to 1.34 for red oak and from 0.23 to 1.75 for red pine (Table 3 ). This confirms that the spruce specimens make sounds more clearly than the others. Within a species, the amplitudes apparently increase with repeated heat treatment (Figure 9). However, their correlations $\left(R^{2}\right)$ are poor, as seen in Table 3.

For all specimens except the controls of the lowest pitches (Specimen no. 1) of red oak and red pine, the amplitudes of the 1st mode resonance frequencies (about $1,000 \mathrm{~Hz}$ ) were higher than those of the 2nd mode resonance frequencies (about 5,000 Hz) whether they were heat treated or not. After the first heat treatment, the exceptional specimens, one of red oak also showed the same pattern (Figure 10). This could confirm that heat treatment stabilizes the acoustic properties of wood.

Logarithmic decrement changes by heat treatment

The logarithmic decrement of wood influences its acoustic properties. Many researchers (Kang et al., 2008; Kang and Jung, 1988; Norimoto, 1982, 1987; Okano, 1991; You and Jung, 1997; Yano, 1992) reported that the wood used for good sounding boards has a high dynamic modulus of elasticity to density ratio and lower damping ratio.

Table 3. The differences of the amplitudes of the 1st mode between the heat treated and the control specimens

\begin{tabular}{|c|c|c|c|c|c|c|c|c|}
\hline \multirow{2}{*}{ Species } & \multirow{2}{*}{$\begin{array}{c}\text { Specimen } \\
\text { no. }\end{array}$} & \multirow{2}{*}{ Con } & \multicolumn{4}{|c|}{ Repetition of heat tretment } & \multicolumn{2}{|c|}{ Linear regression } \\
\hline & & & $\mathrm{H} 1$ & $\mathrm{H} 2$ & H3 & $\mathrm{H} 4$ & Slope & $\mathrm{R}^{2}$ \\
\hline \multirow{8}{*}{ spruce } & 1 & 1.74 & 1.72 & 1.80 & 2.30 & 2.94 & 0.30 & 0.80 \\
\hline & 2 & 1.79 & 1.79 & 2.23 & 2.17 & 1.98 & 0.07 & 0.34 \\
\hline & 3 & 0.73 & 1.11 & 1.43 & 2.63 & 1.50 & 0.31 & 0.47 \\
\hline & 4 & 1.39 & 1.45 & 1.43 & 2.44 & 1.64 & 0.15 & 0.28 \\
\hline & 5 & 2.04 & 1.76 & 0.82 & 2.00 & 2.17 & 0.05 & 0.02 \\
\hline & 6 & 1.77 & 1.11 & 1.12 & 1.11 & 2.12 & 0.07 & 0.05 \\
\hline & 7 & 090 & 0.87 & 0.82 & 0.77 & 1.60 & 0.13 & 0.36 \\
\hline & 8 & 1.22 & 0.55 & 0.88 & 1.15 & 1.30 & 0.08 & 0.16 \\
\hline \multirow{8}{*}{ red oak } & 1 & 0.35 & 0.61 & 0.50 & 0.41 & 0.48 & 0.01 & 0.01 \\
\hline & 2 & 0.30 & 0.66 & 0.53 & 0.44 & 0.50 & 0.02 & 0.05 \\
\hline & 3 & 0.33 & 0.51 & 0.42 & 0.23 & 0.71 & 0.05 & 0.17 \\
\hline & 4 & 0.46 & 0.55 & 0.78 & 0.68 & 0.63 & 0.05 & 0.39 \\
\hline & 5 & 0.79 & 0.71 & 0.66 & 1.34 & 0.99 & 0.10 & 0.35 \\
\hline & 6 & 0.94 & 0.67 & 1.00 & 1.34 & 1.10 & 0.10 & 0.41 \\
\hline & 7 & 0.50 & 0.60 & 0.84 & 1.13 & 0.72 & 0.10 & 0.38 \\
\hline & 8 & 0.85 & 0.68 & 0.47 & 0.89 & 0.85 & 0.02 & 0.04 \\
\hline \multirow{8}{*}{ red pine } & 1 & 0.23 & 0.82 & 0.35 & 0.51 & 1.06 & 0.13 & 0.39 \\
\hline & 2 & 1.01 & 0.66 & 1.44 & 1.70 & 1.46 & 0.19 & 0.54 \\
\hline & 3 & 0.26 & 0.84 & 0.39 & 0.35 & 0.84 & 0.07 & 0.14 \\
\hline & 4 & 1.55 & 0.71 & 1.16 & 1.43 & 1.75 & 0.11 & 0.20 \\
\hline & 5 & 1.51 & 0.81 & 1.42 & 1.44 & 1.30 & 0.02 & 0.01 \\
\hline & 6 & 1.02 & 1.02 & 0.70 & 1.14 & 1.36 & 0.08 & 0.28 \\
\hline & 7 & 1.44 & 0.96 & 0.72 & 0.78 & 0.98 & -0.11 & 0.37 \\
\hline & 8 & 0.95 & 0.88 & 1.20 & 1.13 & 0.74 & -0.02 & 0.02 \\
\hline
\end{tabular}



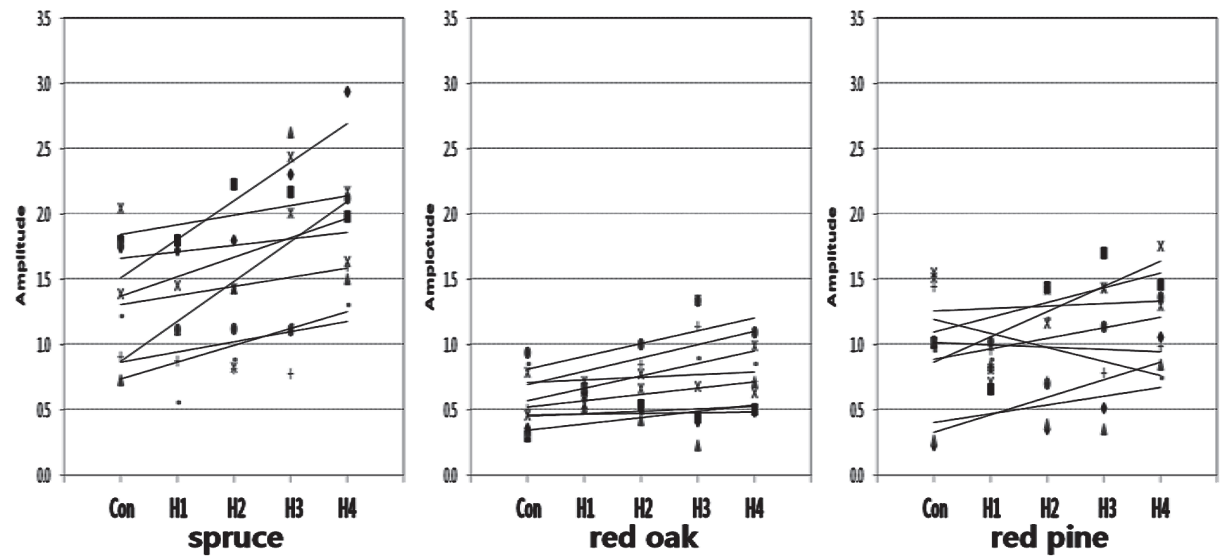

Fig. 9. The resonant amplitude changes by heat treatment on the $1^{\text {st }}$ resonant mode of spruce, red oak and red pine.
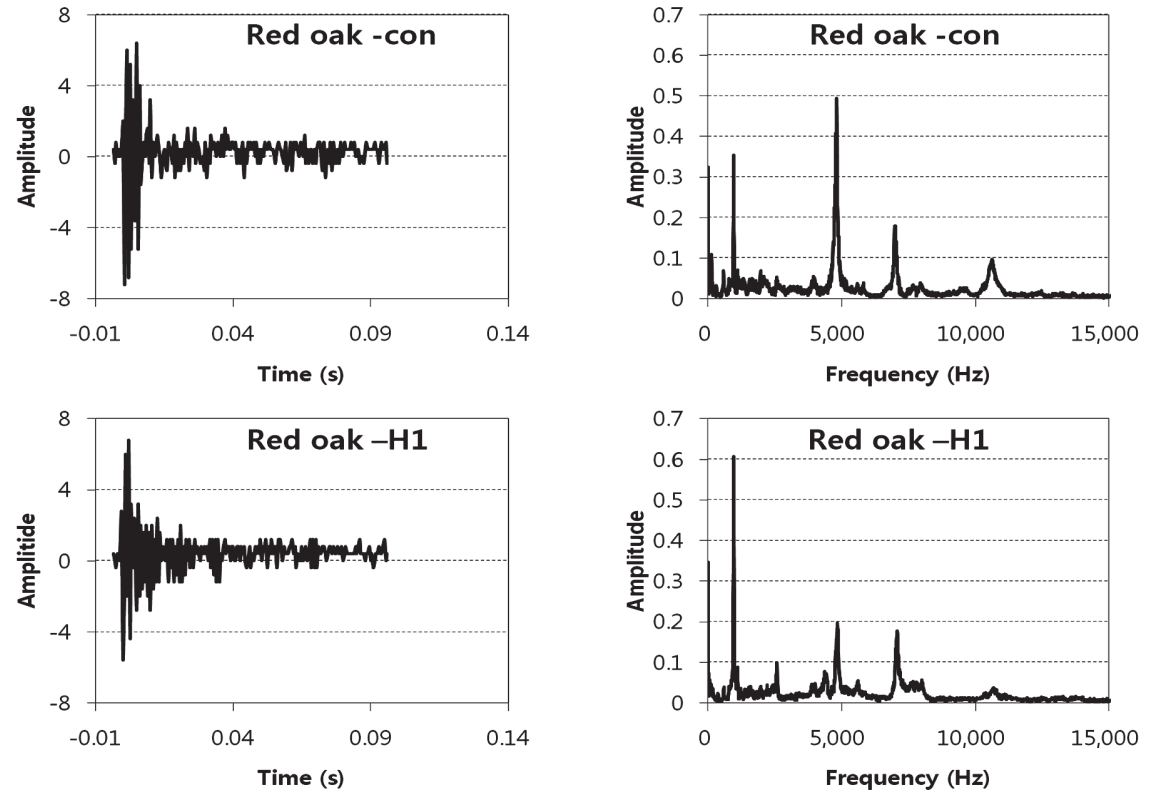

Fig. 10. Comparison of control and heat treated wood on the resonant amplitude of red oak.

Damping ratio, internal friction and logarithmic decrement are related to energy which is converted to heat when a body is vibrated by external force. Norimoto (1982) indicated that a sounding board described as good by a piano expert shows a low ratio of internal friction to dynamic $\operatorname{MOE}\left(Q^{-1} /{ }^{\prime}\right)$. In this study we estimated the logarithmic decrement change of wood resulting from heat treatment. In spruce, logarithmic decrement is not significantly altered by heat treatment for specimens no. 1, 2, 4 and 6, as shown in Figure 11 and Table 6. However, the logarithmic decrement of specimen no. 3 decreased and then increased depending on repetition of heat treatment. Therefore, heat treatment has no consistent effect on logarithmic decrement in the wooden xylophone keyboard. In the case of red oak, the logarithmic decrement increased with repeated heat treatment in the low frequency range, but this trend inverted such that the logarithmic decrement decreased in the high frequency range. Finally, in the case of pine, the logarithmic decrement increased as a result of heat treatment in both frequency ranges, but less so in the high frequency range. Norimoto (1987) reported that the damping ratio was mainly influenced by the S2 layer orientation of the cell wall. These results indicate that heat treatment may causes changes in microscopic cell wall orientation and logarithmic decrement of heat-treated wood.

\section{CONCLUSIONS}

The effect of heat treatment on the acoustic properties of three species with different densities (spruce, red oak and red pine) was studied by investigating the resonant frequencies, resonant amplitudes and logarithmic decrements using the free vibration method. The following conclusions were obtained:

1. For all three species, the 1 st mode resonance frequencies of the control specimens were reversely influenced by the oven-dry densities at all pitches.

2. The 1 st mode resonance frequencies decreased with repeated heat treatment, and the higher pitch speci- 

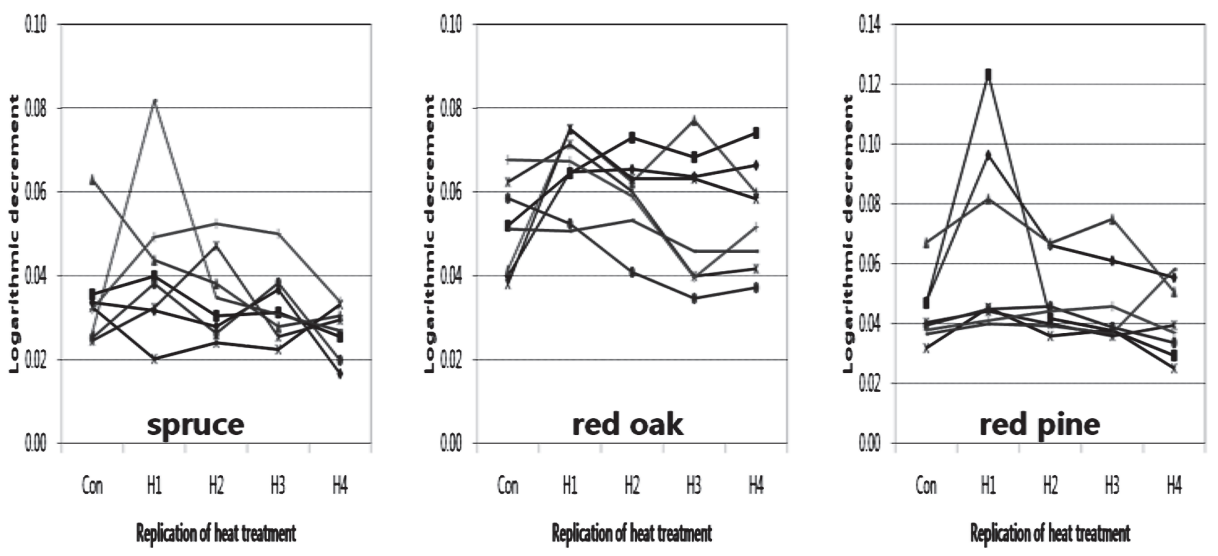

Fig. 11. Logarithmic decrement changes due to the heat treated specimens of spruce, red oak and red pine.

Table 4. Logarithmic decrement changes due to the heat treatment on the sample specimen

\begin{tabular}{cccc}
\hline & \multicolumn{3}{c}{ Species } \\
\cline { 2 - 4 } Specimen no. & Yezo spruce & $\begin{array}{c}\text { Northern } \\
\text { red oak }\end{array}$ & $\begin{array}{c}\text { Japanese } \\
\text { red pine }\end{array}$ \\
\hline 1 & $\bigcirc$ & $\boldsymbol{\Delta}$ & $\Delta$ \\
2 & $\bigcirc$ & $\boldsymbol{\Delta}$ & $\triangle$ \\
3 & $\boldsymbol{\nabla}$ & $\boldsymbol{\Delta}$ & $\boldsymbol{\nabla}$ \\
4 & $\bigcirc$ & $\boldsymbol{\Delta}$ & $\bigcirc$ \\
5 & $\triangle$ & $\boldsymbol{\nabla}$ & $\bigcirc$ \\
6 & $\bigcirc$ & $\boldsymbol{\nabla}$ & $\bigcirc$ \\
8 & $\triangle$ & $\boldsymbol{\nabla}$ & $\bigcirc$
\end{tabular}

$\bigcirc$ :not changed, $\boldsymbol{\Delta}$ :increased, $\triangle$ :increased and then decreased, :decreased

mens were more affected.

3. The spruce specimens were most affected by heat treatment at all pitches, while the red oak specimens were least affected.

4. The power spectrum intensities of the 1st mode resonance frequencies ranged from 0.55 to 2.94 for spruce, from 0.23 to 1.34 for red oak and from 0.23 to 1.75 for red pine. This confirms that the spruce specimens made sounds more clearly than the others.

5. The specimens with higher resonant amplitudes at the 2nd mode resonance frequencies than those at the 1st mode were stabilized by heat treatment.

6. Effects of heat treatment on the logarithmic decrements of acoustic signals varied depending on the species and pitch.

\section{ACKNOWLEDGMENTS}

This study was carried out with the support of 'Forest Science \& Technology Projects (Project No.
S211415L010130)' provided by Korea Forest Service, and with the support of 'Research Base Construction Fund Support Program' funded by Chonbuk National University in 2015.

\section{REFERENCES}

Hearmon R. F. S. 1966 . Theory of the vibration testing of wood Forest Product J. 16(8): 29-40

Kang H, Y., H. S. Byeon, W. H. Lee, B. S. Park, J. H. Park. 2008. Study on physical properties of domestic species I: sorption, thermal, electrical and acoustic properties of Pinus Densiflora. Mokchae Konghak 36(3): 70-84 (in Korean)

Kang W., and H. S. Jung. 1988. Studies on the free vibrational properties of traditional and replaceable species for sounding board. Mokchae Konghak 16(3): 48-64 (in Korean)

Kim D. Y., K. Y. Jang and K. J. Kwon. 2011. The effects of low temperature heat treatment on the yield of holo-cellulose of wood 2011 Proceedings of the Korean Society of Wood Science and Technology Annual Meeting. pp. 300-301 (in Korean)

Norimoto M. 1982. Structure and properties of wood used for musical instruments I. On the selection of wood used for piano sound boards. Mokuzai Gakkaishi 28(7): 407-413

Norimoto M. 1987. Specific Young's modulus and quality of coniferous wood. Mokuzai Gakkaishi 33(7): 545-551

Okano T. 1991. Acoustic properties of wood. Mokuzai Gakkaishi 37(11): 991-998

Tjeerdsma B., Boonstra M., Pizzi A., Tekely P., Militz H. 1998. Characterisation of thermally modified wood: molecular reasons for wood performance improvement. Holz Roh-Werkst 56: $149-153$

Wikberg H., Maunu S. 2004. Characterisation of thermally modified hards and softwoods by 13C CPMAS NMR. Carbohydr Polym. 58: $461-466$

Yano H., Yamada T., Minato K. 1986. Changes in acoustical properties of Sitka Spruce due to reaction with formaldehyde. Mokuzai Gakkaishi 32(12): 984-989

Yano H., Kanou N., Mukudai J. 1990. Changes in acoustical properties of Sitka Spruce due to saligenin treatment. Mokuzai Gakkaishi 36(11): 923-929

Yano H., Matsuoka I., Mukudai J. 1992. Acoustical properties of wood for violins. Mokuzai Gakkaishi 38(2): 122-127

Yoo T-K, Jung H-S. 1997. Effect of moisture contents and density of Paulownia tomentosa on Acoustical Properties. Mokchae Konghak 25(2): 61 66 (in Korean) 